\title{
Mediating Role of Spousal Support on Internalized Stigma and Marital Satisfaction among depressive Patients
}

\author{
${ }^{a}$ Muhammad Asim Nawaz, ${ }^{b}$ Lubna Saeed, ${ }^{c}$ Iqra Mushtaque \\ a Assistant Professor, Lyallpur Business School, Government College University Faisalabad, Pakistan \\ Email: asimkahlon@gcuf.edu.pk \\ ${ }^{\mathrm{b}}$ PhD Philosophy, Ural Federal University, Yekaterinburg, Russia \\ Email: lubnasaeed58@gmail.com \\ ${ }^{\mathrm{c}}$ Department of Psychology, Bahauddin Zakariya University, Bahadur Sub-Campus, Layyah, Pakistan \\ Email: iqra.fatima89@gmail.com
}

\begin{tabular}{l}
\hline ARTICLE DETAILS \\
\hline History: \\
Accepted 16 December 2021 \\
Available Online December 2021 \\
\\
\hline Keywords: \\
Mental Illness, Stigma, \\
Depression, Marital Satisfaction, \\
Spouse Support
\end{tabular}

JEL Classification:

$P_{3} 6$

DOI: $10.47067 /$ real.v4i4.207

\section{ABSTRACT}

There are surprising benefits of being married. Married people have lower stress and are less likely to be depressed. However, depression is not an exemption for married people. In our society people undergoing depression are stigmatized as mentally ill. Ideal marriage is supposed to have good understanding and friendly relationship. So the effect of spousal support received by diagnosed depression patient and the level of marital satisfaction attained by socially stigmatized spouse is the subject of this study. This is a cross sectional study. Purposive sampling was used to collect data from one hundred twenty individuals, in which one of the partners diagnosed with depression recruited from Services Hospital Lahore, CMH Lahore, Mayo Hospital and CMH Kohat. The minimum duration of illness was one year and minimum qualification was metric. After obtaining inform consent Beck Depression Inventory, Internalized Stigma of Mental Illness scale, Couple Satisfaction Index and spousal support scale respectively. Macro PROCESS for mediation, t-test analysis and ANOVA were used to analyze the data. The results revealed a strong relationship in mental illness related stigmatization and marital satisfaction in our society with mediating role of spousal support. Depressed husband showed lower marital satisfaction in spite of getting more support by their spouse. While depressed women seem to be satisfied as compared to men. Although demographic variables like love marriage, arrange marriage, education, family system and duration of illness had a greater impact on marital satisfaction. This study finding provide information for the therapist can work in areas of depressed married individuals those Internalized stigma affects the quality of life, self-esteem and sense of well-being that is indispensible to the marital satisfaction.

(C) 2021 The authors. Published by SPCRD Global Publishing. This is an open access article under the Creative Commons AttributionNonCommercial 4.0 


\section{Introduction}

The Marital Satisfaction is a wider term which covers overall satisfaction of an individual marital life. Satisfaction is an umbrella term and encompasses several elements to contribute in relationship satisfaction. Literature has identified several factors which may influence marital satisfaction. In the context of marital life, researchers investigated attachment styles for marital satisfaction (Driver \& Gottman, 2004), depression and marital adjustment (A, Jaffer et al., 2018), conflict patterns (Caughlin, 1999), communication (Ciarrochi, 2008) and environmental factors such as couple support system, finance, employment, and illness (Sokolski \& Hendrick, 1999; Rizwan et al., 2021). Moreover researcher has stressed to study marital satisfaction among people having physical illness and mental illness. Within the mental illness group stigma has been studied as a significant variable not only effecting treatment of mental illness but also effect marital satisfaction.

Depression is one of the most reported disorders among the psychiatric population visiting for clinical consultation in adults, and it is more common in women (41.9\%) than men (29.3\%), (NIMH, 2018). Depression is described by low mood or loss of concentration or pleasure, additionally comprising of major symptoms of weight loss or gain, insomnia or hyper insomnia, psychometric anxiety or retardation, fatigue, feeling of worthlessness, inability to think or give attention to and suicidal ideation (American Psychiatric Association, 2013). Women are experiencing depression more than twice to men in 10 to 25 years of age. They can also experience depression at any stage of their life. Women have got several life roles like wife, mother, daughter, employee, friend, sister, care giver and so on. The difficulty of all these roles can cause ups and downs throughout life. Sometimes change in mood might cause by an argument with friend or due to hormonal changes. Women tend to emotional, experience more guilty feelings and unhappy when they are facing stress and social pressure (G. Christina, 2017).

Moreover Christina, (2017) estimated that minimum six million men in the U.S suffer from emotional disturbance once a year. Men do not usually understand or acknowledge their own symptoms of depression. Depression was known as female disorder. This stereotypical concept still lingers but men who have the acceptance of illness recognizing it and took appropriate treatment. Men with depression have aggression, apathy, irritable mood and sometimes hostile. Depression is completely different from other mental sicknesses but patients are stigmatized due to negative nature of the illness. Depressive people appear unattractive and become unreliable. Facing such societal Disapproval makes patients shameful and incommunicative and they may even stop taking proper treatment. A serious contributive issue is that people do not know that they are in depression. They often understand their condition as a sign of weakness (Lewis Wolpert, 2001).

There is evidence that interpersonal problems especially in the marital context are associated with the development of depression (Bodenmann, 2006). Chronister, (2013) argued that people experienced negative attitudes towards them due to depression. Societal stigma and internalized stigma with illness also hamper the personal satisfaction. Burke \& Weir, (2010) reported that husband and wife discuss almost everything with each other that is important in a relationship; it erases the stress effects and enhances the wellbeing. Despite the fundamental importance only few studies are available in literature on spousal support and quality of marital satisfaction in socially anxious couples and their idealistic relationship. Social support would possibly check with the means of relieving depression, stress and anxiety. Spouse equivalent support refers to the perception of taking care of each other, and resources may embrace nurturing tangible or intangible emotions to providing a way of happiness among individuals (Levy et al., 2017). 
Studies explored the issues associated with the marital satisfaction but support by partner is ignored in the literature especially in the context of Pakistan. When spousal support is functioning as an intervening variable it would be decreasing the effect of anxiety and depression symptoms (Rodin et al., 2007). Pina \& Bengston, (1993) investigated that wives who were glad about their spouse showed relatively higher level of positive relation, intimacy and competition in their marriage and stated less distrustful feelings than those wives who were less happy by their husbands. Therefore it is important to study the role of spousal support in internalizing mental illness related stigma and level of marital satisfaction.

Pakistan is a country of 204 million people and has only 1 practitioner for every $10 \mathrm{~K}$ individuals suffering from any kind of mental illness. Similarly in Pakistani culture women experience more stigmatization as compared to men (Khan, $\mathrm{N}$ et al., 2015; Mushtaque, Waqas, et al., 2021). In this context, it is utmost important to study the effect of mental illness related stigma on marital satisfaction. This study provides unique findings by analyzing the intervening role of spousal support in mental illness related stigma and its subsequent effect on marital satisfaction. Our findings are helpful for the couples to understand the important factors of marriage life success and satisfaction. Furthermore, this study has filled the gap in literature by providing the important findings on the spousal support for their stigmatized life partner and subsequent level of marital satisfaction received by depression patients.

\section{Methodology}

\subsection{Objectives}

The first objective of this study was to find out the impact of spouse support in the relationship with mental illness related stigmatized individual (depression patient) and subsequent marital satisfaction received by depression patients. The second objective of this study was to investigate demographic difference in marital satisfaction of men and women diagnosed with depression.

\subsection{Sample}

The purposive sampling was used to collect data for study. The sample for the current study was collected from Psychiatric departments of the hospitals located in Lahore. The study comprised of total 120 married participant undergoing depression. The cross sectional study has following inclusion criteria: Clinical diagnosed patients of depression according to DSM-V with minimum duration of 1 year and duration of marriage was at least two year. Patient's ages ranged from 25 to 45 years. Participants were literate enough to read the questionnaire in Urdu language.

\subsection{Instruments}

\subsubsection{Internalized Stigma of Mental illness (ISMI, 2011)}

Mental illness stigma is measured through ISMI that contains twenty nine items concerning Perceived Discrimination, Feeling of Alienation, Stigma Resistance, Stereotype Endorsement and Social Withdrawal. In present study, translated tool was used (Rasool, F et all., 2011). Higher scores on these queries indicated a lot of resistance to stigma and thus less internalized stigma. The take a look at test reliability of this scale is .92. Cronbach alpha worth of the scales is nice .82. But the Internal Consistency of the subscales is Alienation .64, for Social Withdrawal is .69 and Stereotype Endorsement is .63. Jennifer. Boyd. (2004).

\subsubsection{Couple Satisfaction Index (CSI)}

A thirty two-items scale was developed to measure the partner satisfaction during a relationship. This index contains thirty two items with diverse response scale format. CSI-32 scores 
will vary from 0 -161. The higher level of scores indicates the high level of relationship satisfaction and below falling scores $=104.5$ indicate notable dissatisfaction. Rogge, R. D. \& Funk, J. L. (2007)

In the present study tool was translated into Urdu language. The reliability of the Urdu translated scale was 0.80 . Scale coding is as $0-5$. o indicates strongly agree and 5 indicates strongly disagree. Some items of the scale have reversed scoring.

\subsubsection{Spouse/ Partner Support Scale}

A 6-item self-administered questionnaire. The Cronbach alpha of the size is good .86. Scale Coding is as 1 indicate A lot, 2 is for some, 3 is for a little and 4 indicate the not at all. Items were recoded so higher scores replicate higher level of partner support (Schuster et al., (1990). In the present study tool was translated into Urdu language. The reliability of the Urdu translated scale was 0.86 .

\subsubsection{Beck Depression Inventory (BDI)}

A twenty one-item self-administered inventory. The original scale of BDI was developed by Beck and Steer 1993. Urdu custom made by Khan 1996. It is designed to measure the psychological features, behavioral and somatic component of Depression. Items scoring are based on four point rating scale. $\mathrm{o}$ indicates the minimum and 3 indicates the maximum score. High score on BDI shows the High level of Depression.

\subsection{Procedure}

In this study we have a tendency to examine data from 120 married depression diagnosed individuals living in Urban. Individuals were contacted to participate in research and provided us absolute data about their marital life. The primary inclusion criteria for study was that individuals ought to be diagnosed Depression for as a minimum one year at the time of information taking. Additionally, those individuals were approached for data collection who had attended a minimum of $10^{\text {th }}$ school so they had the ability to readout and perceived the instruments that were translated in Urdu language. Participants initially read \& signed on inform consent form. All instruments were arranged in a way that participants initially completed a demographic form, followed by measure of depression screening tool - Urdu, followed by Internalize mental illness stigma Questionnaire a measure of - Urdu, Spousal support Scale- Urdu and after that marital satisfaction index- Urdu.

After these procedures, a telephone contact number was given to the participants to sort out any question associated with instruments. Once the participants were through with their instruments, they were invited to convey their complete contact information if they needed to collect an outline of the results of the current research.

\subsection{Statistical Analysis}

The data of the study was analyzed by PROCESS and independent sample t- test analysis. PROCESS is a macro for SPSS that conducts observed variable moderation and mediation. In the present research we use PROCESS for the mediation. Mediation is a one variable affects a second variable that in return affects a third variable. PROCESS analysis (mediation) was used to see the Spousal Support would mediate the relationship between mental illness related stigma and marital satisfaction in depressive individuals.

The independent sample t-test was used to examine the difference in groups. It can compare the mean score of the two different groups of peoples. The present study was aimed to investigate 
demographic differences in marital satisfaction of men and women diagnosed with depression.

\section{Results}

\subsection{Mediation Analysis}

Mediation of variable was found through Process developed by Andrew and Hayes (2019). Fourth model of mediation were tested. In fourth model independent variable mental illness related stigma was added as a predictor, spousal support as a mediator and couple satisfaction added as outcome.

Table 1: Direct effect of Mental Illness related Stigma as predictor, Perceived Spousal Support as mediator and Couple Satisfaction as outcome $(\mathrm{N}=120)$

\begin{tabular}{|l|l|l|l|l|}
\hline & \multicolumn{2}{|c|}{ Spousal Support } & \multicolumn{2}{l|}{ Couple Satisfaction } \\
\hline & $B$ & $S E$ & $B$ & SE \\
\hline Internalized Stigma & -.049 & .074 & $-.87^{*}$ & 1.03 \\
\hline Depression & $-.73^{* *}$ & .087 & & \\
\hline$R^{2}$ & .38 & & .10 & \\
\hline
\end{tabular}

Note; $b=$ co-efficient, $S E=$ Standard Error, $R 2=$ Variance

Table 1 shows that mental illness related stigma has the significantly negative effect on couple satisfaction, ( $\mathrm{B}=-.049$, SE.074, $\mathrm{P}<.05)$ with 10\% variance. Similarly, mental illness related stigma has the significantly negative effect on spousal support, $\left(\mathrm{B}=-.87^{*}, \mathrm{SE} 1.03, \mathrm{P}<.05\right)$ with $17 \%$ of variance. To covariate stigmatization due to the depression significantly predicts poor spousal support and less marital satisfaction.

Table 2: Direct effect of Spousal Support on Couple Satisfaction

\begin{tabular}{|l|l|l|l|l|}
\hline \multicolumn{2}{|l|}{ Couple Satisfaction } & SE & SE & $95 \% C L$ \\
\hline & & & $L L$ & $U L$ \\
\hline Spousal Support & $.002^{*}$ & .006 & .010 & .015 \\
\hline$R^{2}$ & .017 & & & \\
\hline
\end{tabular}

Note; Note; $\mathrm{b}=$ co-efficient, $\mathrm{SE}=$ Standard Error, $\mathrm{CI}=$ Confidence interval, $\mathrm{LL}=$ lower limit, $\mathrm{UL}=$ upper limit

Table 2 illustrate that spousal support has significant mediating relationship between mental illness related stigma and couple satisfaction.

Table 3: Indirect effect of mental illness related stigma (predictor) on Couple Satisfaction (outcome) through Spousal Support (mediator)

\begin{tabular}{|l|l|l|l|l|}
\hline Couple Satisfaction & B & $S E$ & $95 \% C L$ & $U L$ \\
\hline & & & $L L$ & .014 \\
\hline Internalized Stigma & -.002 & .009 & -.023 & .023 \\
\hline
\end{tabular}

Note; Note; $b=$ co-efficient, $S E=$ Standard Error, $C I=$ Confidence interval, $L L=$ lower limit, $U L=$ upper limit 
Table 3 shows that spousal support has insignificant mediating relationship between mental illness related stigma and couple satisfaction.

Table 4: Mean, Standard Deviations and t- values of gender wise differences on Mental illness related Stigma, Spousal Support and Marital Satisfaction for male and female diagnosed with Depression $(\mathrm{N}=120)$

\begin{tabular}{|c|c|c|c|c|c|c|c|}
\hline \multirow[t]{3}{*}{ Variables } & \multirow{2}{*}{\multicolumn{2}{|c|}{$\begin{array}{c}\text { Male } \\
(n=67)\end{array}$}} & \multicolumn{2}{|r|}{ Female } & \multirow[b]{3}{*}{$t$} & \multirow{2}{*}{\multicolumn{2}{|c|}{$95 \% C L$}} \\
\hline & & & & $(n=53)$ & & & \\
\hline & $M$ & $S D$ & $M$ & $S D$ & & $L L$ & $U L$ \\
\hline Internalized Stigma & 61.8 & 13.4 & 62.4 & 10.8 & .60 & -3.1 & 5.89 \\
\hline Marital Satisfaction & 123.1 & $15 \cdot 3$ & 120.0 & $15 \cdot 7$ & 1.03 & -2.6 & 8.49 \\
\hline Spousal Support & $7 \cdot 4$ & 1.0 & $7 \cdot 3$ & 1.1 & 0.7 & -.25 & 0.54 \\
\hline Beck Depression & $29 \cdot 3$ & 10.4 & 31.1 & 10.2 & -1.3 & -6.37 & 1.17 \\
\hline
\end{tabular}

Table 4 shows differences in male and female on scale that is marital satisfaction. In the sample male scores are high on measurement of marital satisfaction i.e., $\{\mathrm{t}(118)=1.0, \mathrm{P}>.05\}$ on the other hand female scores are high on internalized stigma and have less spousal support.

Table 5: Mean, Standard Deviation and t- value of family system wise differences on Mental illness related Stigma, Perceived Spousal Support and Marital Satisfaction $(N=120)$

\begin{tabular}{|c|c|c|c|c|c|c|c|}
\hline \multirow[t]{3}{*}{ Variables } & \multicolumn{2}{|c|}{ Nuclear } & \multicolumn{2}{|l|}{ Joint } & & & \\
\hline & \multicolumn{2}{|c|}{$(n=59)$} & \multicolumn{2}{|c|}{$(n=61)$} & & \multicolumn{2}{|c|}{$95 \% C L$} \\
\hline & $M$ & $S D$ & $M$ & $S D$ & $t$ & $L L$ & $U L$ \\
\hline Internalized Stigma & 63.7 & 11.05 & 63.1 & 13.05 & .45 & -3.4 & 5.5 \\
\hline Marital Satisfaction & 122.7 & $15 \cdot 3$ & 120.4 & 15.2 & .69 & -7.5 & 3.63 \\
\hline Spousal Support & $7 \cdot 5$ & 1.0 & 7.2 & 1.1 & $0.49^{*}$ & .00 & .78 \\
\hline
\end{tabular}

$d f=118,{ }^{*} p<.05,{ }^{*} p<.01$

Table 5 showed that individuals having nuclear family were high marital satisfaction as compare to individuals who are living in joint family system. Individual perceived high spousal support that were living in nuclear family system than the individuals were living in joint family system i.e., $\left\{\mathrm{t}(118)=0.49^{*}, \mathrm{P}<.05\right\}$.

Table 6: Mean, Standard Deviation and t- value of nature of marriage wise differences on Internalized Stigma of Mental Illness, Perceived Spousal Support and Marital Satisfaction of individuals diagnosed with Depression $(\mathrm{N}=120)$

\begin{tabular}{|l|l|l|l|l|l|c|c|}
\hline Variables & Arrange & \multicolumn{3}{l}{ Love } & \multicolumn{3}{c|}{} \\
\hline & $(n=80)$ & $(n=40)$ & & \multicolumn{2}{c|}{$95 \%$ CL } \\
\hline & $M$ & $S D$ & $M$ & $S D$ & $t$ & $L L$ & $U L$ \\
\hline Internalized Stigma & 62.7 & 12.98 & 64.07 & 11.0 & -.57 & -5.81 & 3.21 \\
\hline Marital Satisfaction & 123.4 & 15.5 & 118.4 & 14.5 & 1.6 & -.86 & 10.7 \\
\hline Spousal Support & 7.4 & 1.1 & 7.2 & 1.0 & .76 & -.25 & .58 \\
\hline
\end{tabular}

$d f=118,{ }^{*} p<.05,{ }^{* *} p<.01$ 
Table 6 demonstrate the significant differences in individual based on marriage type which are arrange and love marriage on marital satisfaction, internalized stigma and spousal support, these differences illustrate that people through love marriage experienced more internalized stigma, less marital satisfaction and perceived low spousal support as compare to arrange marriage.

Table 7: One way ANOVA showing mean, standard deviation, education differences on Mental illness related Stigma, Perceived Spousal Support and Marital Satisfaction of individuals diagnosed with depression $(\mathrm{N}=120)$

\begin{tabular}{|c|c|c|c|c|c|c|c|}
\hline & Metric & Intermediate & Graduation & Post graduate & & & \\
\hline & $(n=44)$ & $(n=16)$ & $(n=24)$ & $(n=36)$ & & & \\
\hline Variables & $\mathrm{M}(\mathrm{SD})$ & $\mathrm{M}(\mathrm{SD})$ & $\mathrm{M}(\mathrm{SD})$ & $\mathrm{M}(\mathrm{SD})$ & df & $\mathrm{f}$ & $\mathrm{p}$ \\
\hline Stigmatization & $60.5(10.9)$ & $64.0(10.2)$ & $62.2(11.1)$ & $48.7(9.2)$ & 3 & 1.81 & .147 \\
\hline Marital Satisfaction & $120.1(15 \cdot 3)$ & $120.8(16.3)$ & $122(14.5)$ & $123 \cdot 7(15.6)$ & 3 & .387 & .76 \\
\hline Spousal Support & $7.1(1.05)$ & $7.0(.90)$ & $7.0(1.0)$ & $7.4(1.1)$ & 3 & .31 & .81 \\
\hline
\end{tabular}

Note. Between group $\mathrm{df}=3$, within group $\mathrm{df}=116$, group total $\mathrm{df}=119,{ }^{*} \mathrm{p}<.05,{ }^{* *} \mathrm{p}<.0$

Table 7 depicted that educated individuals shows more positive attitudes towards stigmatization $(\mathrm{F}(3,116)=1.81, \mathrm{p}<.0005)$, have more marital satisfaction and support by their life partners. Results indicate that metric and intermediate individuals have equal level of marital satisfaction. While intermediate group shows negative attitudes towards stigmatization and have low spousal support.

Table 8: Mean Standard Deviation and t-value of duration of illness wise differences on Internalized Stigma of Mental Illness, Perceived Spousal Support and Marital Satisfaction of married individuals diagnosed with Depression. $(N=120)$

\begin{tabular}{|l|l|l|l|l|l|l|l|}
\hline \multicolumn{2}{|c|}{ Variables } & $1-2 Y$ & \multicolumn{3}{l|}{$3-5 Y$} & \multicolumn{3}{c|}{} \\
\hline & $(n=84)$ & $(n=36)$ & $M 5 \%$ CL & \multicolumn{3}{c|}{95} \\
\hline & $M$ & $S D$ & $M$ & $S D$ & $t$ & $L L$ & $U L$ \\
\hline Internalized Stigma & 64.4 & 12.7 & 61.2 & 9.6 & 1.19 & -5.23 & 21.0 \\
\hline Marital Satisfaction & 122.0 & 14.5 & 120.1 & 16.3 & .72 & -2.25 & 8.6 \\
\hline & & & & & & & \\
Spousal Support & 7.3 & 1.1 & 7.5 & 1.0 & -.76 & -3.47 & .83 \\
\hline
\end{tabular}

$d f=118,{ }^{*} p<.05,{ }^{*} p<.01$

Table 8 demonstrates that duration of illness was found significant differences with internalized stigma, marital satisfaction and spousal support. Results further revealed that individuals who had less duration of diagnosed depression experienced more stigmatization. Similarly, individuals who had less period of depression stigmatization have more marital satisfaction. Individuals having three to four years of duration of illness having more years of married life they attain more spousal support.

\section{Discussion}

Marital Satisfaction is significant area of study in family psychology. It encompasses multiple aspects of married life and married individuals. A sole hallmark of this relationship is that since the two people merry all of life upcoming or previous shortfall becomes shared and to be dealt mutually with understanding to each other's, potentials and limitations. 
Mental illness unlike physical illness has an additional burden of stigmatization that goes hand in hand with the individual suffering. In culture like Pakistan when there is little awareness about psychological problems, people tend to hide the secret of their psychological illness with fear of getting cold response from others.

In this scenario a married individual directly need support from his or her spouse to help his or her out of this miserable circumstances responsibilities (domestic \& external) to shield criticism of other family members or close ones.

It was hypothesized that spousal support would mediate the relationship between mental illness stigmatization and marital satisfaction in men and women". The mediation model 4 matrixes showed that internalized stigma has significantly negative effect on couple satisfaction. Similarly, internalized stigma has the significantly negative effect on spousal support. To covariate stigmatization due to the depression significantly predicts poor spousal support and less marital satisfaction. Further results revealed that spousal support has significant mediating relationship between internalized stigma and couple satisfaction. (Table 1 )

Khan \& Aftah (2013) study support the third hypothesis that spousal support is important factor ha that increase or decrease the marital satisfaction and also predicts depression. Spouses that they express their feeling to one another can influence their behavior toward one another.

The results of the process analysis regarding the internalized stigma of mental illness and marital satisfaction of depressed individuals as presented in (Table 2 and 3) which demonstrate that spousal support effect.

Research evidences for example, Gabriel. B \& Georgia (2010) reported the relationship among depression and broken marital cooperation is all around recorded. They concluded marital satisfaction and stigmatization due to depression significantly impact each other. This study favored that individuals with less duration of diagnosed with depression experienced more stigmatization. Similarly, individuals who had less period of depression and experience less stigmatization have more marital satisfaction (Table 8).

Another study by Khan, $\mathrm{N}$ et al., (2015) concluded that male experience the lower level of discrimination and stigma as compare to women. Women are on high risk that faced the stigma and discriminated due to their mental illness. On contrary, the present study showed that male and female both are experiencing stigmatization in their lives. Women experienced depression regarding more as in compare to men (Table 4). Due to the stigmatization by the society that causes avoidance of participation in particular life areas. Marital satisfaction could decrease as the level of stigmatization increased. These results indicate that there is difference in men and women internalized stigma and marital satisfaction. Women experienced more mental illness stigmatization and less marital satisfaction as compare to men. People with depression are frequently dependent on their loved ones who are sticking by the patient's fear. One of the close people should continually be available to support the affected person. Result showed (Table 5) people living with joint family system faced stigmatization of their illness equally to those individuals who were living in nuclear system. Thus family system has no so much difference in experiencing the stigmatization.

Moreover, differences in love marriage and arrange marriage demonstrate that individuals through love marriage experienced more internalized stigma and less marital satisfaction than 
individuals married through arrange marriage (Table 6). Q. Farah, (2007) study supports the present study results where she concluded that marital issues adding to mental disorders. In Pakistan parents usually chose the life partners for their adult children. It is an idea that arrange marriages are to hold families close. As in arrange marriage parents try to marry in close relatives and cousin in that manner they have high possibilities of adjustment because of same tradition and custom. It is also said by this way spouses keep strong bounding with the family.

Another difference was found on educational level (Table 7). Highly educated individuals who were diagnosed with depression in the current sample were experienced less stigmatization high marital satisfaction than the less educated individuals. Waqas. A \& et al., (2014) above mentioned findings were support that educated people have awareness and exposure about the mental illness problems and have positive attitudes towards.

Similarly differences in duration of illness were found in mental illness related stigma and marital satisfaction. Results revealed (Table 8) those individuals who had less period of depression have more stigmatization but individuals having more years of married life they attain marital satisfaction. Miller., et al (2013) study support the present results, they were concluded that depression caused the less marital satisfaction.

Chronister. J, (2013) study support the present study results, where he concluded that spousal support decrease the risk of depression and increase the marital satisfaction. Male has high marital satisfaction as compare to female (Table 4) whereas results showed that male received more spousal support as compare to female.

An indigenous study by Khan \& Aftab (2013) studied perceived social support among depression and marital satisfaction. Support from life partner prevents disputes from turning into vital behavior and stop raise in conflicts. In Pakistani society, a marriage generally regarded as relationship between families rather than only between the concerned couple (Fazal bhoy, 2006; Mushtaque et al., 2021). Family system of Pakistani society is particularly powerful in couple marital life. In a joint family systems relative's share issues and difficulties. Many individuals take this interference as an uninvited interference and this may cause inconveniences ( Ajmal \& Fatima, 2012). In the present investigation individuals having nuclear family were high marital satisfaction as compare to individuals who are living in joint family system (Table 5). Individual perceived high spousal support that is living in nuclear family system than the individuals living in joint family system (Table 5). Differences were found in individuals based on marital type which is arranged marriage and love marriage on their marital satisfaction and spousal support. These differences illustrate that people through love marriage experienced more internalized stigma, less marital satisfaction and perceived low spousal support as compare to arrange marriage (Table 6).

Moreover, educational differences were found in (Table 7) educated people have more support by their spouses and have more satisfied in their married life than the less educated individuals. Similarly differences in duration of illness were found significant difference in spousal support and marital satisfaction. Results revealed (Table 8) those individuals who had less period of depression have more marital satisfaction but individuals having more years of married life they attain more spousal support.

According to the Epstein \& Baucom,(2002) who explain that spouses experience depression in any part of their life. Duration of illness was found significant differences with internalized stigma, 
marital satisfaction and spousal support (Table 8). Results further revealed that individuals with less duration of diagnosed depression experienced more stigmatization. Similarly, individuals who had less period of depression stigmatization have more marital satisfaction. Individuals having three to four years duration of illness and more years of married life they attain more spousal support.

Wood., et al (2007) reported that individuals who are obliged they approach the problem emotional social support, positive reinterpretation, instrumental social support. Individuals perceived high spousal support by living in nuclear family system than the individuals living in joint family system.

Perceived social support in depression would be a vital variable that predicts martial satisfaction. Weak communication between husband and wife caused several problems and decrease marital satisfaction. In current study individuals have low spousal support that may decrease the marital satisfaction and increase the effect of mental illness stigmatization.

\section{Conclusion}

The present study set up that there is a strong relationship between internalized mental illness stigmatization and marital satisfaction in our society with mediating role of spousal support. Both male and female suffering from psychological illness like depression faced stigmatization and has lower marital satisfaction although spousal support (marital empathy, emotional support) is a dominant factor. Results revealed that both male and female experienced the associated stigma due to their mental illness. Depressed husbands showed lower marital satisfaction even they have received support by their spouse. Support by spouse enhanced marital satisfaction. While depressed women seem to be satisfied as compared with men. The present effort further informs the differences in social specific phenomena like family system arrange and love marriage. The results demonstrate that male and female experiencing the stigma due to their illness equally in joint and nuclear family system. Arrange marriage individuals are more marital satisfaction and high spousal support as compare to love marriage. Similarly nuclear family system produces more spousal support as compare to joint family system. Further results illustrate that people with less duration of illness experienced more stigmatization and individuals who had less period of depression have more marital satisfaction. Individuals having three to four years duration of illness and more years of married life they attain more spousal support.

This study gives proof of concept and exciting new understanding about impact of mental illness stigma on marital satisfaction. The findings of the present study could add in improving the understanding among spouses and counselors to improve marital satisfaction.

\section{References}

Abbas, J., Aqeel, M., Abbas, J., Shaher, B., A., J., Sundas, J., \& Zhang, W. (2019). The moderating role of social support for marital adjustment, depression, anxiety, and stress: Evidence from Pakistani working and nonworking women. Journal of Affective Disorders, 244(244), 231-238. https://doi.org/10.1016/j.jad.2018.07.071

American Psychiatric Association. (2014). Diagnostic and Statistical Manual of Mental Disorders: DSM-5 (5th edition)2014 102 Diagnostic and Statistical Manual of Mental Disorders: DSM-5 (5th edition) Washington, DC American Psychiatric Association 2013 xliv+947 pp. 9780890425541(hbck);9780890425558(pbck) £175 \$199 (hbck); £45 \$69 (pbck). Reference Reviews, 28(3), 36-37. https://doi.org/10.1108/rr-10-2013-0256 
Boyd Ritsher, J., Otilingam, P. G., \& Grajales, M. (2003). Internalized stigma of mental illness: psychometric properties of a new measure. Psychiatry Research, 121(1), 31-49. https://doi.org/10.1016/j.psychres.2003.08.008

Caughlin, J. P., \& Vangelisti, A. L. (1999). Desire for change in one's partner as a predictor of the demand/withdraw pattern of marital communication. Communication Monographs, 66(1), 6689. https://doi.org/10.1080/03637759909376463

Corrigan, P. W., \& Rao, D. (2012). On the Self-Stigma of Mental Illness: Stages, Disclosure, and Strategies for Change. The Canadian Journal of Psychiatry, 57(8), 464-469. https://doi.org/10.1177/070674371205700804

Fatima, M., \& Ajmal, M. A. (2012). Happy marriage: a qualitative study. Pakistan Journal of Social and Clinical Psychology, 9(2), 37-42.

Funk, J. L., \& Rogge, R. D. (2007). Testing the ruler with item response theory: Increasing precision of measurement for relationship satisfaction with the Couples Satisfaction Index. Journal of Family Psychology, 21(4), 572-583. https://doi.org/10.1037/0893-3200.21.4.572

Gabriel, B., Beach, S. R. H., \& Bodenmann, G. (2010). Depression, Marital Satisfaction and Communication in Couples: Investigating Gender Differences. Behavior Therapy, 41(3), 306-316. https://doi.org/10.1016/j.beth.2009.09.001

Gallagher, N. (2006). Encyclopedia of Women and Islamic Cultures: Family, Body, Sexuality and Health, Volume 3, edited by Suad Joseph. Leiden: Brill Academic Publishers, 2006. 564 pages, illustrations, appendix, bibliography, indices. US\$326.oo (Cloth) ISBN 90-04-128-190. Middle East Studies Association Bulletin, 40(2), 242-244. https://doi.org/10.1017/soo26318400049968

Hatch, D. (2008). Factors That Influence the Association Between Adult Attachment and Marital Satisfaction. All Graduate Theses and Dissertations, (161). Retrieved from https://digitalcommons.usu.edu/etd/161

Khan, F., \& Aftab, S. (2013). Marital Satisfaction and Perceived Social Support as Vulnerability Factors to Depression.

Khan, N., Kausar, R., Khalid, A., \& Farooq, A. (2015). Gender Differences among Discrimination and Stigma Experienced by Depressive Patients in Pakistan. Pakistan Journal of Medical Sciences, 31(6). https://doi.org/10.12669/pjms.316.8454

Levy, M., Burns, R. J., Deschênes, S. S., \& Schmitz, N. (2017). Does Social Support Moderate the Association Among Major Depression, Generalized Anxiety Disorder, and Functional Disability in Adults With Diabetes? Psychosomatics, 58(4), 364-374. https://doi.org/10.1016/j.psym.2017.03.004

Mohammadi, K., Samavi, A., \& Ghazavi, Z. (2016). The Relationship Between Attachment Styles and Lifestyle With Marital Satisfaction. Iranian Red Crescent Medical Journal, 18(4). https://doi.org/10.5812/ircmj.23839

Mushtaque, I., Rizwan, M., Abbas, M., Khan, A. A., Fatima, S. M., Jaffri, Q. A., Mushtaq, R., Hussain, S., Shabbir, S. W., Naz, R., \& Muneer, K. (2021). Inter-Parental Conflict's Persistent Effects on Adolescent Psychological Distress, Adjustment Issues, and Suicidal Ideation During the COVID-19 Lockdown. OMEGA - Journal of Death and Dying, o03022282110543. https://doi.org/10.1177/00302228211054316

Mushtaque, I., Waqas, H., \& Awais-E-Yazdan, M. (2021). The effect of technostress on the teachers' willingness to use online teaching modes and the moderating role of job insecurity during COVID-19 pandemic in Pakistan. International Journal of Educational Management, ahead-ofprint(ahead-of-print). https://doi.org/10.1108/ijem-07-2021-0291

NIMH» The National Institute of Mental Health Strategic Plan. (2018). Retrieved from www.nimh.nih.gov website:

reports/index.shtml http://www.nimh.nih.gov/about/strategic-planning- 
Qadir, F., Khalid, A., Haqqani, S., Zill-e-Huma, \& Medhin, G. (2013). The association of marital relationship and perceived social support with mental health of women in Pakistan. BMC Public Health, 13(1). https://doi.org/10.1186/1471-2458-13-1150

Rizwan, M., Ahmad, T., Qi, X., Murad, M. A., Baig, M., Sagga, A. K., Tariq, S., Baig, F., Naz, R., \& Hui, J. (2021). Social Media Use, Psychological Distress and Knowledge, Attitude, and Practices Regarding the COVID-19 Among a Sample of the Population of Pakistan. Frontiers in Medicine, 8. https://doi.org/10.3389/fmed.2021.754121

Smith, L., Heaven, P. C. L., \& Ciarrochi, J. (2008). Trait emotional intelligence, conflict communication patterns, and relationship satisfaction. Personality and Individual Differences, 44(6), 1314-1325. https://doi.org/10.1016/j.paid.2007.11.024

Sokolski, D. M., \& Hendrick, S. S. (1999). Fostering marital satisfaction. Family Therapy: The Journal of the California Graduate School of Family Psychology, 26(1).

Walen, H. R., \& Lachman, M. E. (2000). Social Support and Strain from Partner, Family, and Friends: Costs and Benefits for Men and Women in Adulthood. Journal of Social and Personal Relationships, 17(1), 5-30. https://doi.org/10.1177/0265407500171001

Zadeh, F. Z., \& Ahmed, Z. F. (2007). Comparing marriages systems with success in marriage in upper income group and educated class of Karachi, Bahria. Journal of Professional Psychology, 2, 61-80 